Bull. Egypt. Soc. Physiol. Sci. 40(2), 103-112

\author{
Bull. of Egyp. Soc. Physiol. Sci. \\ (Official Journal of Egyptian Society for Physiological Sciences) \\ (pISSN: 1110-0842; eISSN: 2356-9514)
}

\title{
Potential role of transforming growth factor $\beta 1$ and brain derived neurotrophic factor in Alzheimer and multi-infarct dementias.
}

\author{
Omyma G Ahmed ${ }^{1}$, Eman MH khedr ${ }^{2}$, Hanaa MM Sayed ${ }^{1}$, and Asmaa MS Gomaa ${ }^{1}$ \\ ${ }^{1}$ Medical Physiology Department, ${ }^{2}$ Neurology and Psychiatry Department, ${ }^{1,2}$ Faculty of Medicine, ${ }^{2}$ Assiut University \\ Hospital, ${ }^{1,2}$ Assiut University, ${ }^{1,2}$ Egypt.
}

Received: 3 Feb 2020

Accepted: 1 May 2020

Available online: 1 July 2020

\section{Keywords}

- Alzheimer dementia $(\mathrm{AD})$.

- Brain derived neurotrophic factor (BDNF).

- Multi-infarct dementia (MID).

- Transforming growth factor $\beta 1$ (TGF $\beta 1)$.

\begin{abstract}
Dementia is a progressive cognitive impairment of variable causes. It is considered a global health challenge worldwide as it represents a major comorbidity in the absence of specific treatment or cure. Neurotrophic factors like transforming growth factor $\beta 1$ (TGF $\beta 1$ ) and brain derived neurotrophic factor (BDNF) have been emerged to be a corner stone in synaptic plasticity and memory. Our work aimed to recognize the potential role of TGF $\beta 1$ and BDNF in cognitive impairment estimated by the psychometric tests of Alzheimer and multi-infarct dementias. Thirty demented patients divided into two groups (15 in each group) and 25 healthy matched controls were included. Diagnosis of dementia and estimation of psychometric features using modified mini mental state examination (3MS), memory assessment scale (MAS), and beck depression inventory scale were performed. Serum TGF $\beta 1$ and BDNF were also assessed in all groups. Psychometric tests revealed significant cognitive impairment in both groups compared to normal control. There was significant increase in the serum level of TGF $\beta 1$ and significant decrease in BDNF in both demented groups compared to control group. A significant positive correlation was found between the cognitive impairment and serum TGF $\beta 1$ in both demented groups. In conclusion, our findings suggested that serum TGF $\beta 1$ levels could reflect the severity of dementia regardless its cause, in addition, depletion of BDNF might be a possible mechanism of cognitive deterioration in dementia
\end{abstract}

Corresponding author: Dr. Hanaa Mohammed Mohammed Sayed, Demonstrator of Medical Physiology Department, Faculty of Medicine, Assiut University, Egypt. E-mail: hanaa.dwak@yahoo.com. Tel: 01016113232 


\section{INTRODUCTION}

Dementia is an umbrella term of several causes that refers to progressive cognitive impairment severe enough that interferes with independent living [1]. It is a global health challenge as the incidence of dementia subtypes progressively increases with aging and their number is expected to approach from 66 million to 115 million by 2050 [2]. Therefore, it represents a major comorbidity worldwide in the absence of specific curative treatment [3].

Alzheimer's disease (AD) is the most common and prevalent type of dementia [3]. It is a progressive, irreversible neurodegenerative brain disorder of the elderly, which targets specific areas critical for cognition and emotional behaviors [4]. The etiology of $\mathrm{AD}$ is complex and variable; therefore, $\mathrm{AD}$ acquires a heterogenic clinical presentation [5] with exact underlying mechanisms remain unclear [3]. Several hypotheses have been postulated to clarify the etiology of this multifactorial disorder [6] including "amyloid hypothesis" [7], "inflammation hypothesis" [8], "cholinergic hypothesis" [9], oxidative stress-induced neurotoxicity [4], and "neurovascular hypothesis" [10]. Multi-infarct dementia (MID) was considered the most common type of vascular dementia $(\mathrm{VaD})$ which is the second most common type of dementia after $\mathrm{AD}$ [11]. Cerebrovascular hypothesis [12] in addition to ischemic cholinergic deficit are pathogenic pathways involved in the underlying pathophysiological mechanisms of $\mathrm{VaD}$ [13]. Moreover, neuroinflammation is suggested to be one of the corner stones in the etiopathology of $\mathrm{VaD}[14]$.

Transforming growth factor $\beta 1$ (TGF $\beta 1$ ) is an injury-related cytokine [15]. It plays an important role in the regulation of neuronal development, differentiation, survival and regulated apoptosis under physiological and pathological circumstances [16], besides being a corner stone in synaptic plasticity and memory [17]. Brain derived neurotrophic factor (BDNF) is considered a critical neuromodulator in the central nervous system, as it promotes synaptic plasticity, as well as neuronal survival, and regeneration [18].

The present work aimed to evaluate the cognitive impairment in $\mathrm{AD}$ and MID, using the psychometric tests and to recognize the potential role of TGF $\beta 1$ and BDNF in the cognitive impairment of Alzheimer and multi-infarct dementias.

\section{Subjects and methods}

Our work was conducted between 2016 to 2017 on 30 demented patients (15 patients with Alzheimer dementia, and 15 patients with multiinfarct dementia) aged from 50 to 75 years and 25 matched subjects as control group. Patients below 50 and above 75, patients with other neurological disorders, and patients with psychiatric disorder were excluded. Patients were recruited from the outpatient clinic of the Hospital of Neuropsychiatry, Assiut University.

The study protocol was approved by The Ethics Committee of Faculty of Medicine; Assiut University. An informed consent was signed by the relative accompanying the patient.

All participants were subjected to:

1-History taking including: age, sex, social and economic level, and educational level.

2-Clinical diagnosis of $\mathrm{AD}$ and MID that was carried out according to the Diagnostic and Statistical Manual of Mental Disorders fifth edition (DSM 5) and its recent updates [19].

\section{3-Psychometric tests:}

A) Modified mini mental state examination (MMMSE) or (3MS): 
It is a screening test for dementia with score ranges from 0 to 100 . Higher score indicating less impairment. It estimates cognitive functions including immediate and remote memory, orientation, attention and concentration, language and naming, verbal fluency, and executive function. Total score less than 79 indicates mild to moderate cognitive impairment, while total score $<48$ indicates severe impairment [20].

\section{B) Memory Assessment Scale (MAS):}

MAS assesses three areas of cognitive function which are short-term memory, verbal memory, and visual memory. While total MAS represents verbal + visual memory scores [21].

\section{C) Beck Depression Inventory scale:}

It was done to assess the degree of depression associated with dementia [22].

\section{4-Assesment of serum TGF $\beta 1$ and BDNF using ELISA Kit:}

\subsection{Sample collection:}

Blood samples were collected form all subjects, allowed to clot, centrifuged for $15 \mathrm{~min}$ at $1000 \times \mathrm{g}$ at $2 \sim 8^{\circ} \mathrm{C}$, and then the supernatant was collected. Serum was kept at $-20{ }^{\circ} \mathrm{C}$ until analysis.

\subsection{Sample analysis:}

The serum level of human TGF $\beta 1$ and BDNF were estimated according to the manufacturer manual of human TGF $\beta 1$ (Transforming Growth Factor Beta 1, ELISA Kit, Catalog No: E-EL-H0110 96T- Elabscience Biotechnology, USA), and human BDNF (Brain Derived Neurotrophic Factor, ELISA Kit, Catalog No: E-EL-H0010 96T- Elabscience Biotechnology, USA). Results of serum levels of TGF $\beta 1$ were expressed by $\mathrm{pg} / \mathrm{ml}$, while serum levels of BDNF were expressed by $\mathrm{ng} / \mathrm{ml}$.

\section{Statistical analysis}

Data were analyzed using Statistics Package for Social Sciences (SPSS) version 20. Data were expressed as mean \pm standard deviation (SD). Data of sex and educational level were analyzed using Chi-square test. All other parameters were analyzed by independent samples t-test. Correlations in the studied groups were done using non-parametric Spearman's test. Differences between groups were considered significant when $P$ values were less than 0.05 .

\section{Results}

1-Demographic results of the control, Alzheimer dementia, and multi-infarct dementia groups:

Table [1] showed that there was insignificant difference in age between the control group and MID group while a significant difference in the $\mathrm{AD}$ group against the control was present $(p<0.05)$. There was also no significant difference in sex, social and economic level, and educational level between the control group and the two demented groups.

2-Psychometric results of the control, Alzheimer dementia, and multi-infarct dementia groups:

\section{1-The Modified Mini Mental State examination (3MS):}

Table [2] showed the score of 3MS. It illustrated that there was a significant cognitive decline in both AD group ( $\mathrm{p}<0.001)$ and MID group ( $p<0.01$ ) when compared with the control group.

\section{2- The Memory Assessment Scale (MAS):}

Table [2] demonstrated that there was a significant reduction in all tested memory domains (short term memory, verbal memory, and visual memory) and total score of MAS in AD group $((\mathrm{p}<0.01), \quad(\mathrm{p}<0.001), \quad(\mathrm{p}<0.001)$, and $(\mathrm{p}<0.001)$; respectively) and MID group $((\mathrm{p}<0.01),(\mathrm{p}<0.001)$, 
$(\mathrm{p}<0.001)$, and $(\mathrm{p}<0.001)$; respectively) when compared with the control group.

\section{3-Beck depression Inventory scale:}

Table [2] showed that there was associated significant depression in the AD group $(\mathrm{p}<0.001)$ and MID group ( $\mathrm{p}<0.01)$ against the control group.

3-Biochemical results of TGF $\beta 1$ and BDNF of the control, Alzheimer dementia, and multiinfarct dementia groups:
Figure [1] showed a significant elevation in the serum levels of TGF $\beta 1$ in $\mathrm{AD}$ group $(\mathrm{p}<0.001)$ and MID group $(\mathrm{p}<0.001)$ in comparison to the control group. Furthermore, there was a significant reduction in the serum levels of BDNF in AD group $(\mathrm{p}<0.001)$, MID group $(\mathrm{p}<0.001)$ compared to control group.

Table [1]: Demographic data of the control, Alzheimer dementia, and multi-infarct dementia groups.

\begin{tabular}{|c|c|c|c|}
\hline Group & $\begin{array}{l}\text { Control } \\
(n=25)\end{array}$ & $\begin{array}{l}\text { Alzheimer } \\
\text { dementia } \\
(n=15)\end{array}$ & $\begin{array}{l}\text { Multi-infarct } \\
\text { dementia } \\
(n=15)\end{array}$ \\
\hline Age (year) & $60.7 \pm 6.8$ & $65.7 \pm 5.14^{*}$ & $61.2 \pm 9.0$ \\
\hline $\operatorname{Sex}(M / F)$ & $13 / 12$ & $6 / 9$ & $10 / 5$ \\
\hline $\begin{array}{l}\text { Social and economic } \\
\text { level }\end{array}$ & $87.4 \pm 17.0$ & $83.5 \pm 17.0$ & $88.3 \pm 25.0$ \\
\hline $\begin{array}{l}\text { Education level (less than } \\
6 \text { years education /6-12 } \\
\text { years education /high } \\
\text { education) }\end{array}$ & $15 / 8 / 2$ & $6 / 7 / 2$ & $11 / 3 / 1$ \\
\hline
\end{tabular}

Data presented as mean \pm standard deviation. M/F (male / female) ratio. * Statistically significant against the control group $(\mathrm{p}<0.05)$ using t-test.

Table [2]: Psychometric results of the control, Alzheimer dementia, and multi-infarct dementia groups:

\begin{tabular}{|c|c|c|c|}
\hline Group & $\begin{array}{l}\text { Control } \\
(n=25)\end{array}$ & $\begin{array}{l}\text { Alzheimer } \\
\text { dementia } \\
(\mathbf{n}=15)\end{array}$ & $\begin{array}{l}\text { Multi-infarct } \\
\text { dementia } \\
(n=15)\end{array}$ \\
\hline Total 3MS & $84.5 \pm 12.5$ & $49.7 \pm 17.8^{* * * *}$ & $60.8 \pm 13.6^{* * *}$ \\
\hline \multicolumn{4}{|l|}{ MAS } \\
\hline Short term memory & $65.1 \pm 10.5$ & $55.4 \pm 3.1^{* * *}$ & $57.5 \pm 4.3^{* *}$ \\
\hline Verbal memory & $84.7 \pm 5.4$ & $59.6 \pm 5.2^{* * * *}$ & $63.3 \pm 5.8^{* * *}$ \\
\hline Visual memory & $66.7 \pm 7.5$ & $55.8 \pm 3.0^{* * * *}$ & $57.3 \pm 3.4^{\text {*** }}$ \\
\hline Total & $72.4 \pm 6.4$ & $54.5 \pm 2.9^{* * *}$ & $58.1 \pm 5.8^{* * * *}$ \\
\hline 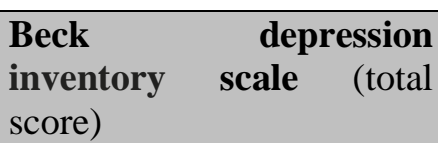 & $8.1 \pm 3.4$ & $19.4 \pm 9.6^{* * * *}$ & $16.5 \pm 7.8^{* * *}$ \\
\hline
\end{tabular}

Data presented as mean \pm SD. ${ }^{*} \mathrm{P}<0.05,{ }^{* * *} \mathrm{P}<0.01$, and ${ }^{* * * *} \mathrm{P}<0.001$ when comparing demented groups $v s$ control group using t-test. Modified mini mental state examination (3MS), Memory assessment scale (MAS). 


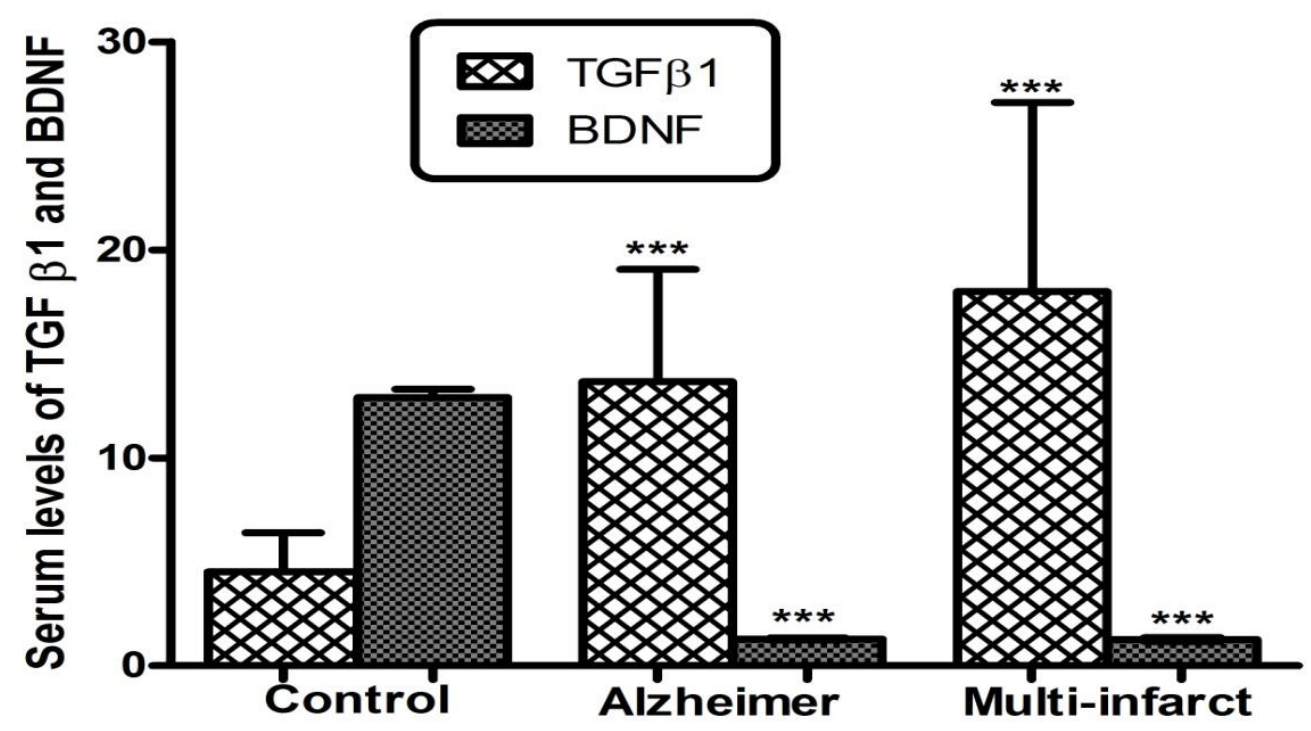

Figure [1]: Serum levels of transforming growth factor $\beta 1$ (TGF $\beta 1$ ) and brain derived neurotrophic factor (BDNF) in the Alzheimer dementia group and multi-infarct dementia group $v s$ the control, ${ }^{* * *} \mathrm{P}<0.001$. Data presented as mean $\pm \mathrm{SD}$.

\section{4-Non-parametric Spearman's correlations:}

As illustrated in table [3], in all demented patients there was a significant positive correlation between the serum level of TGF $\beta 1$ and the score of psychometric tests (3MS and total MAS) $((\mathrm{p}<0.001)$ and $(\mathrm{p}<0.01)$ respectively $)$. This significance might be attributed to the significant positive correlation in both $\mathrm{AD}$ and MID groups $(\mathrm{p}<0.01$ and $\mathrm{p}<0.05$ respectively). However, this significant correlation was not present between subjects of control group ( $p>0.05)$ and between serum level of BDNF and score of psychometric tests in all groups $(\mathrm{p}>0.05)$.

Table [3]: Correlations in control, Alzheimer dementia, and multi-infarct dementia groups:

\begin{tabular}{|c|c|c|c|c|}
\hline Group & \multicolumn{2}{|l|}{ variable } & $\begin{array}{l}\text { Serum TGF } \beta 1 \\
(\mathrm{pg} / \mathrm{ml})\end{array}$ & $\begin{array}{l}\text { Serum BDNF } \\
(\mathrm{ng} / \mathrm{ml})\end{array}$ \\
\hline \multirow{4}{*}{$\begin{array}{l}\text { All patients } \\
(\mathrm{n}=30)\end{array}$} & \multirow[t]{2}{*}{ Total 3MS } & r-value & 0.6 & 0.1 \\
\hline & & P-value & $0.0001^{* * * * *}$ & 0.3 \\
\hline & \multirow[t]{2}{*}{ Total MAS } & r-value & 0.5 & 0.2 \\
\hline & & P-value & $0.003^{* * *}$ & 0.1 \\
\hline \multirow{2}{*}{$\begin{array}{l}\frac{\text { Control }}{(\mathrm{n}=25)} \\
\underline{\underline{n}}\end{array}$} & \multirow{2}{*}{ Total 3MS } & r-value & 0.2 & 0.02 \\
\hline & & P-value & 0.3 & 0.9 \\
\hline \multirow{4}{*}{$\begin{array}{l}\frac{\text { Alzheimer }}{\text { dementia }} \\
\underline{(\mathrm{n}=15)}\end{array}$} & \multirow[t]{2}{*}{ Total 3MS } & r-value & 0.66 & 0.08 \\
\hline & & P-value & $0.0066^{* * *}$ & 0.7 \\
\hline & \multirow[t]{2}{*}{ Total MAS } & r-value & 0.55 & 0.1 \\
\hline & & P-value & $0.03^{*}$ & 0.7 \\
\hline \multirow{4}{*}{$\begin{array}{l}\frac{\text { Multi-infarct }}{\text { dementia }} \\
\underline{(n=15)}\end{array}$} & \multirow[t]{2}{*}{ Total 3MS } & r-value & 0.68 & 0.4 \\
\hline & & P-value & $0.01^{*}$ & 0.1 \\
\hline & \multirow[t]{2}{*}{ Total MAS } & r-value & 0.5 & 0.3 \\
\hline & & P-value & $0.04^{*}$ & 0.4 \\
\hline
\end{tabular}

r-value (Correlation coefficient), P-value (Significance 2-tailed). Spearman's correlation significant if $\left({ }^{*} \mathrm{p}<0.05,{ }^{* *} \mathrm{p}<0.01,{ }^{* * *} \mathrm{p}<0.001\right)$. Total score of modified-mini-mental state examination (3MS), Memory assessment scale (MAS), Transforming growth factor $\beta 1$ (TGF $\beta 1$ ), Brain derived neurotrophic factor (BDNF). 


\section{Discussion}

Dementia is a global health challenge [23]. It has been considered a multifactorial syndrome [24]. Unfortunately, dementia requires high social and economic cost and is reported to be a leading cause of death [25]. The present work evaluated the cognitive impairment in $\mathrm{AD}$ and MID, using the psychometric tests to detect the degree and specific domain of memory affection, and the degree of associated depression. Furthermore, the serum levels of TGF $\beta 1$ and BDNF were estimated to assess the potential role of those neurotrophic factors in the cognitive impairment of these types of dementias.

Demographic data revealed no significant differences in sex, social and economic, and educational levels between the control group and both dementia groups. Age was significantly high only in $\mathrm{AD}$ group as it was considered a major risk factor for its development [26].

Psychometric tests performed in the present work using $3 \mathrm{MS}$ and MAS showed that in both $\mathrm{AD}$ and $\mathrm{MID}$ there were significant impairments in short term memory, verbal memory (including language and learning and memory), and visual memory (including perceptual-motor functions) with variable degree of severity in addition to a significant impairment in the global memory compared to the control group. In $\mathrm{AD}$, this result agreed with Jaswal et al. [27] and Ribeiro et al. [28]. These changes were attributed mainly to the neuronal degeneration affecting the central cholinergic system [27]. Furthermore, the structural damage of the cortical areas vital for cognition via deposition of neurofibrillary tangles with subsequent loss of functional hippocampal synapses might explain these changes according to
Ribeiro et al. [28] and Bohnen et al. [29]. While in MID, these results were consistent with Kalaria et al. [30]. The cognitive impairment detected in MID was reported to be dependent on the volume, number, and location of the infarctions [30], being the frontal lobe which responsible for executive functions is the most vulnerable site to microvascular damage in MID [31]. Also, the cholinergic system damage in those patients could explain learning and memory deficit as reported by Wang et al. [32].

There was a significant depression in both demented groups revealed by Beck depression inventory scale. Depression was an associated symptom secondary to loss of the noradrenergic locus coeruleus neurons in these types of dementia [33]. Our results were consistent with Alzheimer's [8] in AD, and with Al-Adawi et al. [31] in MID.

TGF $\beta 1$ plays a critical role in synaptic plasticity and memory [17]. The present work showed a significant elevation in the serum levels of TGF $\beta 1$ in both patient groups compared to the control group. In $\mathrm{AD}$, this result was in agreement with Lian and Zheng [34] and Zhang et al. [35], who attributed the increased TGF $\beta 1$ level to amyloid beta $(A \beta)$ - induced oxidative stress, neuroinflammation, and activation of astrocytes and microglia and this increased TGF $\beta 1$ could ameliorate neurodegeneration by enhancing $\mathrm{A} \beta$ clearance. On the other hand, Flanders et al. [36] reported that the serum TGF $\beta 1$ was reduced in $\mathrm{AD}$ due to its impaired expression. In MID, our results could be explained by the associated neuroinflammation and oxidative stress in MID as parts of their underlying pathophysiology [14, 37]. Previous work in patients with focal brain lesions but without dementia reported up-regulation of the 
TGF $\beta 1$ in CSF and brain tissue $[38,39]$ which may either mediate neuronal excitotoxic damage through potentiation of $\mathrm{N}$-methyle $\mathrm{D}$-aspertate (NMDA) receptor-dependent neurotransmission, or neuroprotection via alteration of glutamate metabolism in astrocytes [40].

The current work demonstrated a significant positive correlation between the serum levels of TGF $\beta 1$ and the total score of $3 \mathrm{MS}$ and MAS in AD as well as in MID in which higher levels of TGF $\beta 1$ were associated with better cognitive performance suggesting that it provides a neuroprotective effect in both demented groups. Moreover, it might also reflect the severity of cognitive impairment with more severe cases acquiring lower levels of TGF $\beta 1$. However, this correlation was not present in the control group as TGF $\beta 1$ is absent or expressed at a very low levels under physiological condition [34] and so, it is referred as an injury related cytokine[15].

BDNF is currently suggested to be essential for cognition and memory processes [41]. This work revealed significant reduction in the serum levels of BDNF in both demented groups compared to the control group. This was in congruent with Mariga et al. [42] who reported reduced levels of BDNF in postmortem brain examination of $\mathrm{AD}$ patients, and, Passaro et al. [43] who found reduced levels of BDNF gene and its protein expression in $\mathrm{VaD}$. Reduced level of serum BDNF could be a sequel of several interacting factors similar to those implicated in the pathophysiology of dementia like neuronal degeneration of cortical areas critical for cognition [44], accumulation of $A \beta$ oligomers as well as neurofibrillary tangles and hyper phosphorylated tau protein $[42,45,46]$ with subsequent impaired
BDNF trafficking and signaling. Hence, BDNF depletion could be a possible pathophysiological mechanism for deterioration of cognition in these types of dementia.

In conclusion, the present work evaluated cognitive impairment in AD and MID and revealed that cognitive impairment shared common features regardless the type of dementia suggesting that these types exhibit common pathophysiological mechanisms. Depression was a hallmark of dementia regardless its cause which might be a risk factor or part of the dementia syndrome. High serum levels of TGF $\beta 1$ might mediate a neuroprotective function in both types of dementia. BDNF depletion could be a possible pathophysiological mechanism for cognitive deterioration in these types of dementia. Hence, our work elucidated that TGF $\beta 1$ and BDNF are biological markers that could be therapeutic targets for dementia. Furthermore, they might be helpful in early detection and hence early therapeutic intervention to ameliorate the social and economic burden of dementia.

\section{References}

1. van de Haar HJ, Burgmans S, Hofman PA, Verhey FR, Jansen JF, Backes WH. Bloodbrain barrier impairment in dementia: current and future in vivo assessments. Neuroscience and biobehavioral reviews. 49:71-81, 2015.

\section{Arya MA, Manoj Kumar MK, Sabitha} M, Menon KN, Nair SC. Nanotechnology approaches for enhanced CNS delivery in treating Alzheimer's disease. Journal of Drug Delivery Science and Technology.51:297-309, 2019.

\section{Shinjyo N, Parkinson J, Bell J, Katsuno}

T, Bligh A. Berberine for prevention of dementia associated with diabetes and its comorbidities: A 
systematic review. Journal of Integrative Medicine. 2020.

4. Tramutola, Lanzillotta C, Perluigi M, Butterfield DA. Oxidative stress, protein modification and Alzheimer disease. Brain Research Bulletin.133:88-96, 2017.

\section{Santos CY, Snyder PJ, Wu W-C, Zhang}

M, Echeverria A, Alber J. Pathophysiologic relationship between Alzheimer's disease, cerebrovascular disease, and cardiovascular risk: A review and synthesis. Alzheimer's \& Dementia: Diagnosis, Assessment \& Disease Monitoring.7:69-87, 2017.

6. Kurz A, Perneczky R. Novel insights for the treatment of Alzheimer's disease. Progress in Neuro-Psychopharmacology and Biological Psychiatry. 35:37-39, 2011.

7. Tadayon E, Pascual-Leone A, Press D, Santarnecchi E. Choroid Plexus Volume is Associated With Levels of CSF Proteins: Relevance for Alzheimer's and Parkinson's Disease. Neurobiology of Aging. 2020.

8. Alzheimer's A. 2018 Alzheimer's disease facts and figures. Alzheimer's \& Dementia. 14:367-429, 2018.

\section{Roy R, Niccolini F, Pagano G, Politis M.}

Cholinergic imaging in dementia spectrum disorders. European Journal of Nuclear Medicine and Molecular Imaging.43:1376-1386.

10. Bailey TL, Rivara CB, Rocher AB, Hof PR. The nature and effects of cortical microvascular pathology in aging and Alzheimer's disease. Neurological research. 26:573-8, 2004.

\section{Rodríguez García PL, Rodríguez}

García D. Diagnosis of vascular cognitive impairment and its main categories. Neurología (English Edition).30:223-39, 2015.
12. Venkat P, Chopp M, Chen J. Models and mechanisms of vascular dementia. Exp Neurol. 272:97-108, 2015.

13. Kumaran D, Udayabanu M, Kumar M, Aneja R, Katyal A. Involvement of angiotensin converting enzyme in cerebral hypoperfusion induced anterograde memory impairment and cholinergic dysfunction in rats. Neuroscience. 155:626-39, 2008.

14. Belkhelfa M, Beder N, Mouhoub D, Amri M, Hayet $\mathbf{R}$, Tighilt $\mathbf{N}$, et al. The involvement of neuroinflammation and necroptosis in the hippocampus during vascular dementia. Journal of Neuroimmunology. 320:48-57, 2018.

15. Manaenko A, Lekic T, Barnhart M, Hartman R, Zhang JH. Inhibition of TGF- $\beta$ Attenuates Brain Injury and Neurological Deficits in a Rat Model of GMH. Stroke; a journal of cerebral circulation. 45:828-34, 2014.

16. Patel RK, Prasad N, Kuwar R, Haldar D, Abdul-Muneer PM. Transforming growth factor-beta $\quad 1 \quad$ signaling regulates neuroinflammation and apoptosis in mild traumatic brain injury. Brain, Behavior, and Immunity. 64:244-58, 2017.

17. Caraci F, Gulisano W, Guida CA, Impellizzeri AAR, Drago F, Puzzo D, et al. A key role for TGF- $\beta 1$ in hippocampal synaptic plasticity and memory.5:112-52, 2015.

18. Jiang L, Zhang H, Wang C, Ming F, Shi $\mathbf{X}$, Yang M. Serum level of brain-derived neurotrophic factor in Parkinson's disease: a metaanalysis. Progress in Neuro-Psychopharmacology and Biological Psychiatry. 88:168-174, 2019.

19. Association AP. Diagnostic and Statistical Manual of Mental Disorders, fifth edition updates:74, 2018. 
20. Andrew MK, Rockwood K. A five-point change in Modified Mini-Mental State Examination was clinically meaningful in community-dwelling elderly people. Journal of Clinical Epidemiology.61:827-831, 2008.

21. J. Michael Williams PD. Memory Assessment Scale. In Resources PA, editor. p. 103, 1990.

22. Omranifard V, Haghighizadeh $\mathbf{E}$, Akouchekian S. Depression in Main Caregivers of Dementia Patients: Prevalence and Predictors. Adv Biomed Res.7:34-44, 2018.

23.

Espinoza RT. Clarifying the

Relationship Between Benzodiazepines and Dementia. Journal of the American Medical Directors Association. 21:143-5, 2020.

24. Evans TE, Adams HHH, Licher S, Wolters FJ, van der Lugt A, Ikram MK, et al. Subregional volumes of the hippocampus in relation to cognitive function and risk of dementia. NeuroImage.178:129-35, 2018.

25. Andersson J, Oudin A, Sundström A, Forsberg B, Adolfsson R, Nordin M. Road traffic noise, air pollution, and risk of dementia results from the Betula project. Environmental Research. 166:334-9, 2018.

26. Panpalli Ates M, Yilmaz Can F. Which factors can we control the transition from mild cognitive impairment to dementia? Journal of Clinical Neuroscience. 2020.

27. Jaswal G, Swardfager W, Gao F-q, Nestor SM, Ganda A, Cogo-Moreira H, et al. Reduced substantia innominata volume mediates contributions of microvascular and macrovascular disease to cognitive deficits in Alzheimer's disease. Neurobiology of Aging. 66:23-31, 2018.
28. Ribeiro FM, Vieira LB, Pires RGW, Olmo RP, Ferguson SSG. Metabotropic glutamate receptors and neurodegenerative diseases. Pharmacological Research. 115:179-191, 2017.

29. Bohnen NI, Kaufer DI, Hendrickson R, Ivanco LS, Lopresti BJ, Constantine GM, et al. Cognitive correlates of corticalcholinergic denervation in Parkinson'sdisease and parkinsonian dementia. Journal of neurology. 253:242-247, 2006.

30. Kalaria RN, Akinyemi R, Ihara $\mathbf{M}$. Stroke injury, cognitive impairment and vascular dementia. Biochimica et Biophysica Acta (BBA) Molecular Basis of Disease. 1862:915-925, 2016.

31. Al-Adawi S, Braidy N, Essa M, Al-Azri F, Hussain S, Al-Sibani N, et al. Cognitive profiles in patients with multi-infarct dementia: an omani study. Dementia and geriatric cognitive disorders extra.4:271-282, 2014.

32. Wang J, Zhang HY, Tang XC. Cholinergic deficiency involved in vascular dementia: possible mechanism and strategy of treatment. Acta pharmacologica Sinica 30:879888, 2009.

33. Hanagasi HA, Tufekcioglu Z, Emre M. Dementia in Parkinson's disease. Journal of the Neurological Sciences. 374:26-31, 2017.

34. Lian H, Zheng H. Signaling pathways regulating neuron-glia interaction and their implications in Alzheimer's disease. Journal of neurochemistry.136:475-91, 2016.

35. Zhang X, Huang WJ, Chen WW. TGFbeta1 factor in the cerebrovascular diseases of Alzheimer's disease. European review for medical and pharmacological sciences.20:5178-5185, 2016. 
36. Flanders KC, Ren RF, Lippa CF. Transforming growth factor-betas in neurodegenerative disease. Progress in neurobiology.54:71-85, 1998.

\section{Liu Z, Chen H-Q, Huang Y, Qiu Y-H,}

Peng Y-P. Transforming growth factor- $\beta 1$ acts via T $\beta R$-I on microglia to protect against MPP+induced dopaminergic neuronal loss. Brain, Behavior, and Immunity.51:131-143, 2016.

38. Gomes F, de Oliveira Sousa V, Romão

L. Emerging roles for TGF-beta 1 in nervous system development. 413-24 , 2005

39. Slevin M, Krupinski J, Slowik A, Kumar P, Szczudlik A, Gaffney J. Serial Measurement of Vascular Endothelial Growth Factor and Transforming Growth Factor- $\beta 1$ in Serum of Patients With Acute Ischemic Stroke. Stroke.31:1863-70, 2000.

40. Vivien D, Ali C. Transforming growth factor-beta signalling in brain disorders. Cytokine \& growth factor reviews.17:121-8, 2006.

41. van den Buuse $\mathbf{M}$, Buret $\mathbf{L}$, Hill $\mathbf{R}$. Involvement of brain-derived neurotrophic factor (BDNF) in the long-term memory effects of glucocorticoid stimulation during adolescence/young adulthood. Behavioural Brain Research.377:1122-23, 2020.

42. Mariga A, Mitre M, Chao MV. Consequences of brain-derived neurotrophic factor withdrawal in CNS neurons and implications in disease. Neurobiology of Disease. 97:73-9, 2017. 43. Passaro A, Dalla Nora E, Morieri ML, Soavi C, Sanz JM, Zurlo A, et al. Brain-derived neurotrophic factor plasma levels: relationship with dementia and diabetes in the elderly population. The journals of gerontology Series A, Biological sciences and medical sciences.70:294$302,2015$.

44. Castrén E, Kojima M. Brain-derived neurotrophic factor in mood disorders and antidepressant treatments. Neurobiology of Disease. 97:119-26, 2017.

45. Almeida MF, Chaves RS, Silva CM, Chaves JCS, Melo KP, Ferrari MFR. BDNF trafficking and signaling impairment during early neurodegeneration is prevented by moderate physical activity. IBRO Reports. 1, 19-31, 2016.

46. Michalski B, Corrada MM, Kawas CH, Fahnestock M. Brain-derived neurotrophic factor and TrkB expression in the "oldest-old," the 90+ Study: correlation with cognitive status and levels of soluble amyloid-beta. Neurobiology of Aging. 36:3130-9, 2015. 